\title{
Evaluation of Bearing Technology in Direct Drive Electrical Generators
}

\author{
C. Pun ${ }^{1}$, A.S. McDonald ${ }^{2}$, M. Parker $^{3}$ \\ University of Strathclyde, Glasgow,U.K, ${ }^{1}$ chandra.pun@strath.ac.uk, ${ }^{2}$ alasdair.mcdonald@strath.ac.uk, \\ ${ }^{3}$ max.parker@strath.ac.uk
}

Keywords: Direct drive, magnetic bearing, rolling element bearing, air gap flux, electromagnetic forces.

\begin{abstract}
This paper presents an evaluation of mechanical contactless magnetic bearing against the conventional industry standard rolling element bearing in direct drive electrical generators. The evaluations are performed based on the energy consideration and their potential contribution in structural mass reduction of rotor. A cylindrical rolling element bearing is chosen to represent the conventional type and an approximate modelling of magnetic bearing is carried out to evaluate them. A finite element analysis in the rotor structure is performed to estimate its mass and to analyse any potential saving in mass by the use of magnetic bearing.
\end{abstract}

\section{Introduction}

There has been huge increase in offshore wind turbine installation in recent years. According to EWEA, 13\% growth in offshore wind turbine deployment was noted in 2015 over 2014, of which the average turbine size ranges 4 to $6 \mathrm{MW}$ [1]. The offshore deployment means cost of accessing machine becomes challenging and costly. Thus, as the leading wind turbine manufactures are going towards direct drive train solution, its market share has picked up as well [2].

The direct drive electrical conversion system is favoured over the geared system on the grounds of potential improvement in system reliability and reduction in maintenance needs. However, in this low speed system, generator size tends to become large and the efficient mechanical integration without violating electrical and mechanical integrity of the machine becomes more challenging. This would lead the bearing system prone to fail.

Among the various failure modes, bearing failure contributes around $55 \%$ share in large scale generator [3]. Failure in the bearing would result failure in generator. This will have very severe impact with loss of revenue due to downtime and may lead to costly unplanned maintenance cost. The severity of impact is even intensified for failure in offshore wind turbines. Thus, the bearing systems - which are often blamed for their contribution to failure modes and tend to need periodic maintenance - have to be resilient and should have low maintenance requirements, otherwise the benefits of direct drive might be neutralised. Conventional bearing system used in direct drive generator is rolling element bearing.
Considering the failure in bearings, there has been some research going on to find the potential solution to the above problem and alternatives to the conventional bearings. Sarah [4] has presented the design of bearing in direct drive generator of wave energy converter. Although, the conventional bearing system was used, future attention on alternative novel option to achieve contact less operation was mentioned. Shrestha et al. [5],[6] analysed the use of magnetic bearing in direct drive generator. With this new concept it was claimed that the significant structure mass saving could be made as an additional flexibility could be introduced. This potential additional flexibility in structure was achieved by the local control of air gap.

The primary function of bearing systems is to provide an interface between stationary parts and rotating parts. This should be done with minimum friction and reduce the transfer of unwanted loads. Their design and selection are tied to the application and operating environment with different priority over issues mainly related to performance, life span, maintenance and cost. The direct drive generator is a low speed application with high priority for reliability with an additional challenge to maintain a physical gap between stator subject to large electromagnetic forces. In an ideal case, the bearing solution would have: an infinite lifetime; it wouldn't require regular maintenance; if it does need maintenance then it would be easy to maintain; it would enable lightweight generator design; it wouldn't cause downtime of the plant if it fails; and it will provide a mechanism to prevent catastrophic damage to the generator if it does fail. For the economic perspective, the mentioned characteristics would be achieved without capital cost and operating and maintenance costs.

The complete evaluation of these two bearing system would require both technical and economic evaluation. It should also take account of their performance, maintenance requirement, failure rates and ease of repair. In order to accommodate all of these evaluating criteria, extensive data of their operational history regarding failure rate and downtime and cost would be required. Magnetic bearings application in low speed large scale generators are premature compared to the rolling element bearing. Thus, the evaluation based on maintenance and cost are beyond the scope of this paper.

This paper reviews conventional rolling element bearing and magnetic bearing for direct drive electrical generators and evaluates them based on the energy consideration and potential structural mass reduction of the rotor. The baselines of 
generator and bearing systems are detailed in section 2 and the evaluation in the two bearing system are presented in section3.

\section{Evaluation Baseline}

The evaluation of two competing systems used in same application has to be performed based on the common specifications and modelling of application area. In order to achieve this, generator specifications are presented and bearing systems are modelled as below. A radial flux, surface mounted permanent magnet direct drive generator of inner rotor type is used as a baseline. A section of it is presented in figure 1(a) and its specifications are presented in table 1 [7].

\subsection{Generator Specifications}

The generator is integrated to rest of the turbine structures using two bearings as shown in figure 2. It is assumed that the axial loads are borne by main bearing and the evaluation of the bearings is based on the radial loads imposed by generator only.

(a)
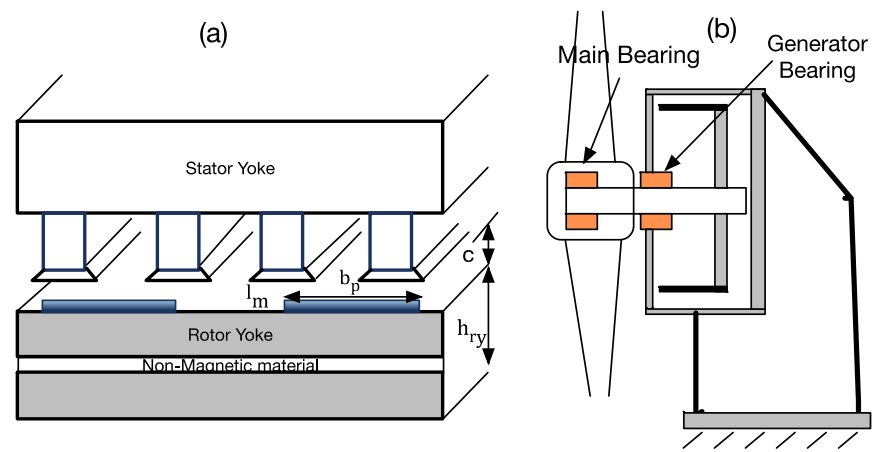

Figure 1: (a) Section of a generator, (b) Configuration of wind turbine to show how generator is integrated to rest of the turbine [8].

Table 1: Specification of generator

\begin{tabular}{|l|l|}
\hline \multicolumn{2}{|c|}{ Generator Specifications } \\
\hline Generator Speed $(\mathrm{rpm})$ & 12 \\
\hline Rotor radius $(\mathrm{m}), \mathrm{R}$ & 3.5 \\
\hline Air gap (mm), c & 7 \\
\hline Rotor yoke height $(\mathrm{mm}), \mathrm{h}_{\mathrm{ry}}$ & 40 \\
\hline Axial length $(\mathrm{m}), l$ & 1.5 \\
\hline Magnet height $(\mathrm{mm}), \mathrm{b}_{\mathrm{p}}$ & 15 \\
\hline Magnet width $(\mathrm{mm}), \mathrm{l}_{\mathrm{p}}$ & 87.5 \\
\hline Rotor structure material & Steel \\
\hline Density $\left(\mathrm{kg} / \mathrm{m}^{3}\right), \rho$ & 7999.5 \\
\hline
\end{tabular}

\subsection{Bearing system}

Bearing systems are modelled based on the design radial loads in the baseline generator. There are wide ranges of choices in selecting types and specifications of rolling element bearing suitable for the nature of application. In this case, a cylindrical rolling element bearing was chosen from the specification provided by SKF based on the radial loads and the rotational speed of the baseline generator [9]. Its dimensions are shown in figure 2(a). (a)
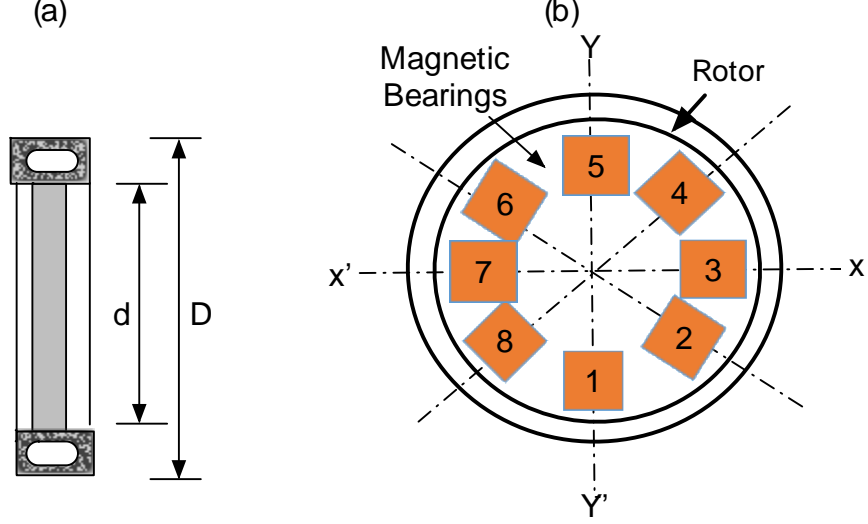

Figure 2: Bearings (a) Cylindrical rolling element bearing, (b) Modelling of magnetic bearings $-45^{0}$ alignment.

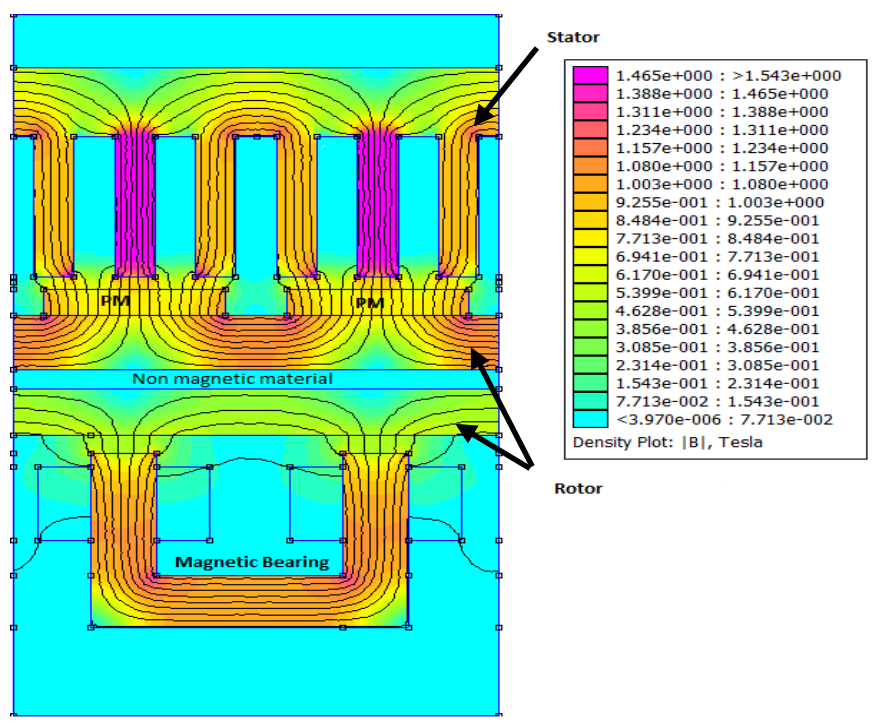

Figure 3: FEMM modelling of a section of generator with magnetic modelling

Table 2: Specifications for rolling element bearing and magnetic bearing.

\begin{tabular}{|l|l|}
\hline \multicolumn{2}{|c|}{ Rolling element bearing } \\
\hline Type & Cylindrical \\
\hline Bore diameter $(\mathrm{m}), \mathrm{d}$ & 1.5 \\
\hline Outer ring diameter $(\mathrm{m}), \mathrm{D}$ & 1.82 \\
\hline Lubrication type & grease \\
\hline Friction coefficient, $\mu$ & 0.0011 \\
\hline Load Type & Radial \\
\hline \multicolumn{2}{|c|}{ Magnetic Bearing } \\
\hline Core leg width $(\mathrm{m})$ & 0.3 \\
\hline Core leg height $(\mathrm{m})$ & 0.9 \\
\hline Total width $(\mathrm{m})$ & 1.37 \\
\hline Total length $(\mathrm{m})$ & 1.5 \\
\hline Number of turn, N & 300 \\
\hline Current density $\left(\mathrm{Amp} / \mathrm{m}^{2}\right), \mathrm{j}$ & 5 E6 \\
\hline Resistivity & 1.68 E-8 \\
\hline Core type & C-structure \\
\hline Core material & Steel \\
\hline Total unit & 8 \\
\hline
\end{tabular}


The magnetic bearings are modelled inside the rotor as shown in figure 2(b). Eight bearings are uniformly distributed inside rotor in order to generate levitation forces required to control the position of rotor in $\mathrm{x}-\mathrm{y}$ plane. Each bearing section consists of 2-leg C-core electromagnets and its specifications are given in table 2. The rotor yoke is separated into inner and outer section by non-magnetic material in order to provide separated flux for rotor's magnet and bearings. FEMM analysis was performed for a bearing section to check the saturation of the core, which is shown in figure 3 . This implies that a varying radially inward force of attraction could be generated over the rotor surface. The control of the forces will be the function of current magnitude controlled by power electronic converters. Detail modelling on the control is beyond the scope of the paper.

\section{Evaluations}

\subsection{Energy Consideration}

Mechanical rolling element bearings don't require external electrical power/energy for their operation but the frictional losses between two moving parts are unavoidable. On the other hand, magnetic bearings in principle eliminate any mechanical contacts between the moving parts. This ideally leads to zero frictional power loss. However, this comes at the expense of external operational power required to produce sufficient levitation forces.

The application of rolling element bearings in electrical machines is quite standardized and there are many "off the shelf" products. So, depending on the choice of application and with the nature of loads it has to bear, one can estimate the specification of bearing required from a manufacturer's catalogue. The power loss in rolling element bearing is due to friction, which basically depends on bearing type, size, operating speed, properties of the material and quality of lubrication. According to SKF, one of the leading bearing manufacturers, power loss, $P_{\mathrm{L}}$, in the cylindrical rolling element bearing can be estimated by equation (1).

$$
\begin{gathered}
P_{\mathrm{L}}=1.05 \times 10^{-4} M n, \\
M=0.5 \mu P d,
\end{gathered}
$$

where $M$ is the total frictional moment of the bearing given by equation (2) assuming good lubrication normal operation condition and constant friction coefficient, $n$ is rotational speed, $P$ is the dynamic equivalent load and $d$ is the bearing bore diameter [9]. Thus the frictional losses can be estimated for the bearing given the speed of the shaft (rated $12 \mathrm{rpm}$ ) and the radial loads imposed by the generator rotor structure are known.

Unlike conventional rolling element bearings there aren't standard relations for estimating extra power required for magnetic bearing tailored to its application in electrical generators. Although this extra power primarily depends on the levitating force of attraction required to prevent physical contact between rotor and stator, it will be heavily influenced by how the magnetic bearing is modelled. Important factors include the bearing placement, the number of bearing units, the design of the windings, what magnetic materials are used in the rotor yoke and magnetic cores along with other factors. In addition to this it will depend on the rigidity of rotor yoke and modes of deformations that the bearing has to deal with. Detailed analysis of the latter two aspects is beyond the scope of this paper.

In order to provide a first approximation of magnetic bearing power consumption, the bearing has been modelled as shown in Figure 2 and 3. The force produced by each leg can be estimated by basic principle of electromagnetic force. For a Ccore electromagnet with $N$ winding turns in both legs and current $i$ flowing through the winding, the electromagnetic force of attraction generated by each leg is given by equations (3) and (4),

$$
\begin{gathered}
F=\frac{B^{2}}{2 \mu_{0}} 2 a=\frac{\mu_{0} a N^{2} i^{2}}{c^{2}}, \\
B=\frac{\mu_{0} N i}{c},
\end{gathered}
$$

where $a$ is the cross section of a C-core leg, $\mu_{0}$ is the permeability of free space, $c$ is air gap between the leg and the rotor yoke and $B$ is the flux density in the air gap given by (4). Below saturation, varying the current can control the amount of the force. The maximum amount of force that can be generated will also depend on the saturation of the core material (equation (4) assumes that the rotor yoke is infinitely permeable).

Power loss in the winding will depend on the current and the resistance of the windings; this is given by (5). Thus the power loss per leg is given by (6),

$$
\begin{gathered}
R=\frac{\rho L}{A}=\frac{2 \rho N(w+l) j}{i}, \\
P_{\mathrm{Cu}}=i^{2} R=2 \rho j N(w+l) i,
\end{gathered}
$$

where $\rho$ is resistivity of the copper, $j$ is current density of the winding, $w$ is width of leg and $l$ is the axial length of the leg. Hence with the idea of force required to produce by a leg, ampere turns required can be estimated by (3) and the corresponding power loss per leg can be approximated by (6). The total power loss will be the product of number of leg used and $P_{\mathrm{Cu}}$.

All of the above assumptions are based on the fact that the radial load borne by the bearings can be estimated. These radial loads imposed on the bearing depend on the position of the rotor structure. Thus this will generate two different scenarios if we only consider the mode 1 deformation of the rotor:

(a) When the rotor is placed centred on its rotational axis such that uniform air gap is maintain throughout the rotor 
surface. In this case, the radial force borne by the bearing will be the force required to support rotor structure against gravity, i.e.

$$
F_{\mathrm{R}}=m_{\mathrm{R}} g \text {. }
$$

(b) When the rotor is offset by a certain distance towards some section of stator it results in a non-uniform flux distribution and results in an imbalance force. Thus the force borne by the bearing will be sum of the weight of the rotor and the imbalance force. This imbalance force is the function of length of displacement and the angle of the orientation of displacement, i.e.

$$
\begin{gathered}
F_{\mathrm{R}}=m_{\mathrm{R}} g+F_{\mathrm{imb}}, \\
F_{\mathrm{imb}}=f(c \pm \Delta \mathrm{c} \cdot \cos \theta) .
\end{gathered}
$$

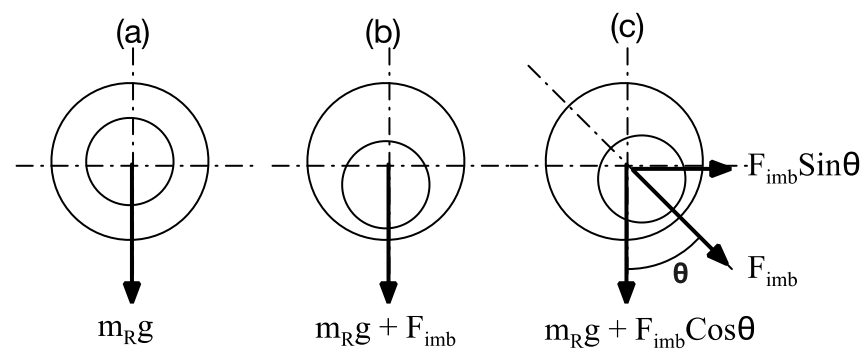

Figure 4: Different rotor positions (a) when rotor is rotor is place centred on its rotational axis, (b) when rotor is displaced vertically downward, (c) when rotor is displaced downward at certain angle.

In figure 5(a), the variation of magnetic flux density with air gap length is plotted on left $y$-axis and the corresponding electromagnetic force of attraction is plotted on right y-axis. It can be clearly observed that both parameters reduce as the air gap length increases. The design air gap length, which is $7 \mathrm{~mm}$ in this case, would result in the flux density of $0.85 \mathrm{~T}$ and the corresponding normal component force of attraction of magnitude $8500 \mathrm{kN}$ over the air gap. If the uniform air gap were maintained over the rotor surface, these forces would cancel out. Any deviation in air gap length would result imbalance forces. Figure 5(b) shows the variation of electromagnetic force with the closer of air gap as the percentage of design value $(7 \mathrm{~mm})$. The maximum allowable deviation in air gap is $10 \%$ of the designed value, which corresponds to the radial load of $1100 \mathrm{kN}$. The total radial load consists of weight of rotor and the varying imbalance force due to non-uniform air gap. The varying imbalance force increases as the air gap length deviates further from the design value and hence the total radial loads on the bearings increases as a result.

The comparison of power consumed by magnetic bearing and power loss in rolling element bearing at different percentage deviation from design air gap length in vertically downward position is presented in figure 6(a). When the rotor is positioned at its centre of rotational axis i.e $0 \%$ deviation in air gap length, magnetic bearing would consume around $3 \mathrm{~kW}$ more power than the rolling element bearing. This power is just to provide sufficient force to support the rotor mass against gravity. Thus, with magnetic bearing, there would always be a base power loss of $3.2 \mathrm{~kW}$ in addition to further power loss in the event of rotor being offset from mean position. One can observe that the power loss in rolling element bearing is very less. However, any deviation in air gap length will become permanent. This means that if a maximum allowable deviation of air gap were caused due to manufacturing inaccuracies, there would be a power loss of $1.5 \mathrm{~kW}$ permanently.

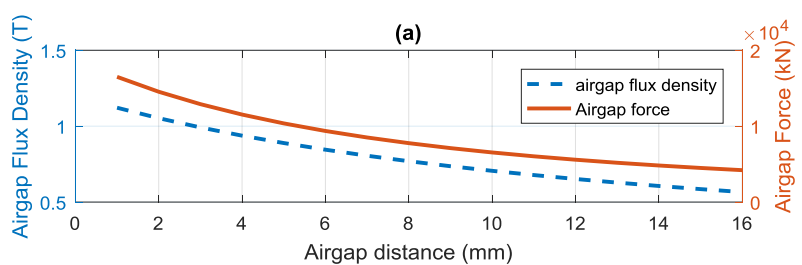

(b)

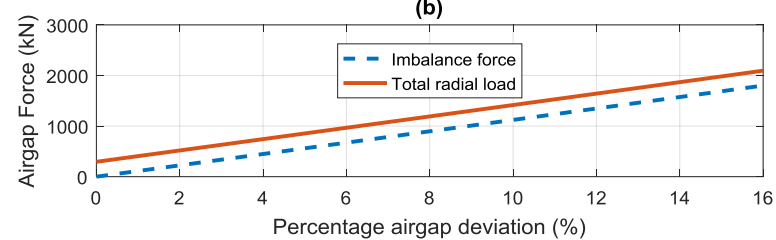

Figure 5: Results (a) Air gap flux density and air gap electromagnetic force against air gap distance, (b) Imbalance electromagnetic force and total force requirements at different air gap downward displacements.
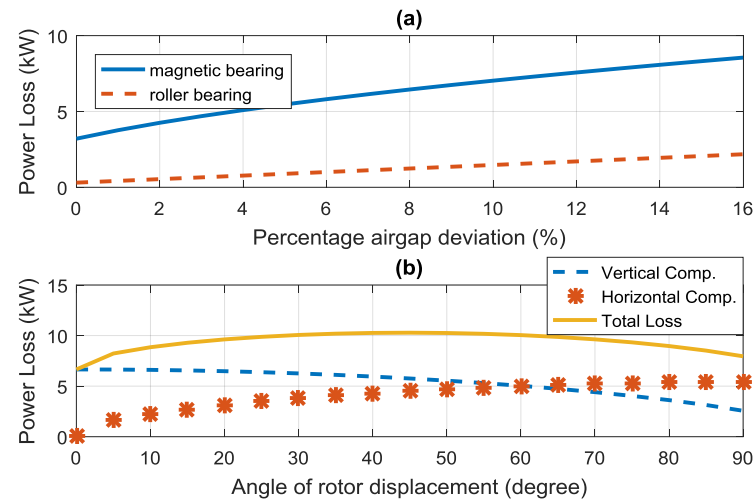

Figure 6: Results (a) Power loss in magnetic bearing and rolling element bearing against percentage deviation from designed air gap length, (b) Power Loss in magnetic bearing when $\Delta c$ is angled downward.

Figure 6(b) presents power required by magnetic bearing when the rotor is offset by maximum allowable deviation angled downward. This creates component of imbalance force on both horizontal and vertical position, which are shown by dotted lines. The resultant imbalance force and the corresponding was maximum when the rotor was angled 45 degree downward.

\subsection{Structural Mass}

Direct drive generators are comparatively huge. In the case of wind turbines, they are preferably designed with low aspect ratio. Thus, for large-scale generators, their structural mass tends to dominate their total mass. Any contribution in reducing this structural mass could potentially benefit in 
having comparatively lighter generator, which in turn reduces its cost and loads on the tower.

Structural mass of a generator depends primarily on the various loads and the stiffness requirements. In an electrical generator, the loads on the structures will be shear and normal stresses, gravity force, unbalanced magnetic pull due to eccentricity, thermal expansion force and centripetal forces [10]. The requirement of the structural stiffness mainly depends on the need to limit deflection of the air gap between the rotor and stator.

For this paper, the structural mass is estimated based on the loads caused by electromagnetic force and the structure is stiff enough to maintain air gap not less than $10 \%$ of the design value. This requires certain amount of thickness of the rotor cylindrical wall and the supporting disk. Thus the mass of the rotor will be given by (10).

$$
\begin{aligned}
m_{\mathrm{R}}=\rho[ & \left.\pi R^{2}-\pi\left(R-t_{\mathrm{w}}\right)^{2}\right] l \\
& +n \pi\left[\left(R-t_{w}\right)^{2}-r^{2}\right] t_{d}
\end{aligned}
$$

where, $n$ is the number of supporting disk required and rest of the parameter as described in $\$ 2$. It is obvious from the relation that as the rest of the dimensions will be fixed in the design phase, the parameters that can be altered include $t_{\mathrm{w}}, t_{\mathrm{d}}$ and $n$.

Broadly there are three approaches that can lead to a reduction in the structural mass of - for example - a rotor:

(1) By reducing the design loads on the structure,

(2) By allowing more tolerance for deflection and therefore allowing the structure to be more flexible,

(3) By providing a shorter or more efficient load path to a notionally infinitely stiff support,

(4) By optimising the design of the structure so that it has an overall better stiffness to mass ratio.

It can be seen that a use of a magnetic bearing can be seen as part approach (1) and part approach (3). The basis of the analysis is shown in figure 7 for $\mathrm{C}$-structure rotor with equivalent radial loads in both bearing configuration. The reduction of design radial loads would be achieved by counteracting attraction force.

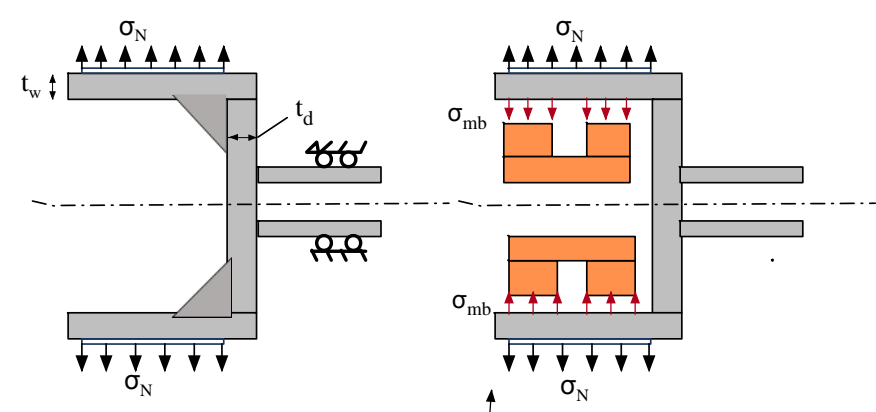

Figure 7: Section of a C-type rotor structure with rolling element bearing (left) and corresponding application of magnetic bearing (right)

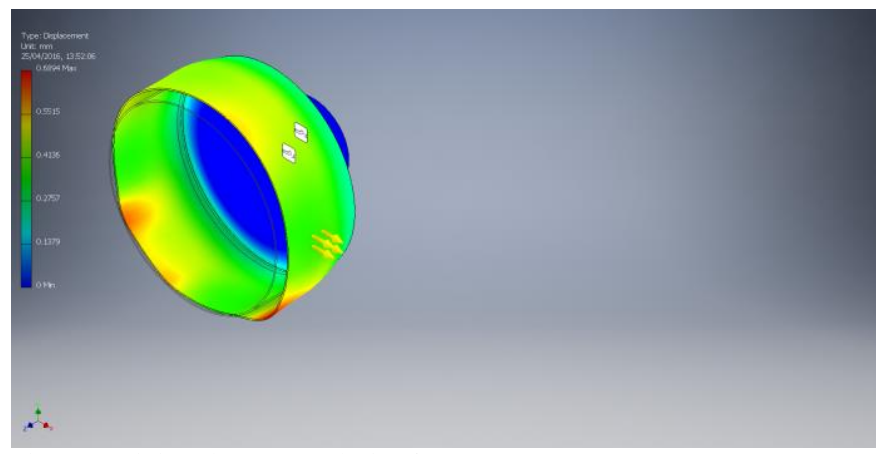

Figure 8: Finite Element Analysis of C-type rotor structure.

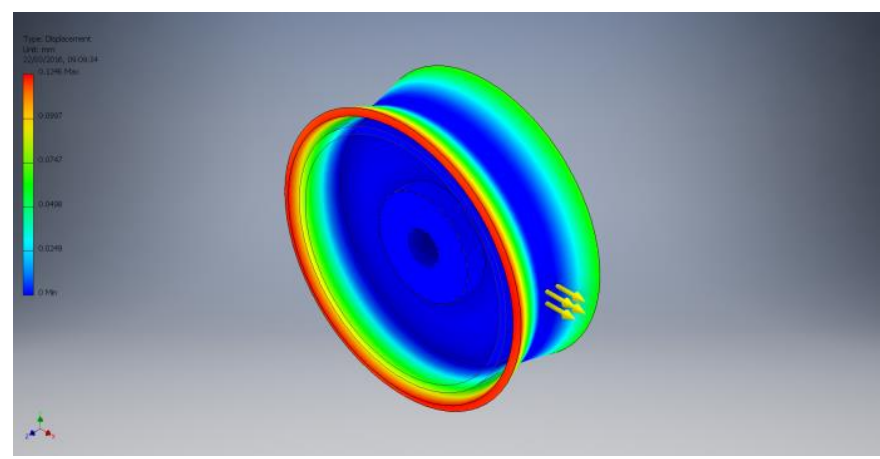

Figure 9: Finite Element Analysis of I-type rotor structure.

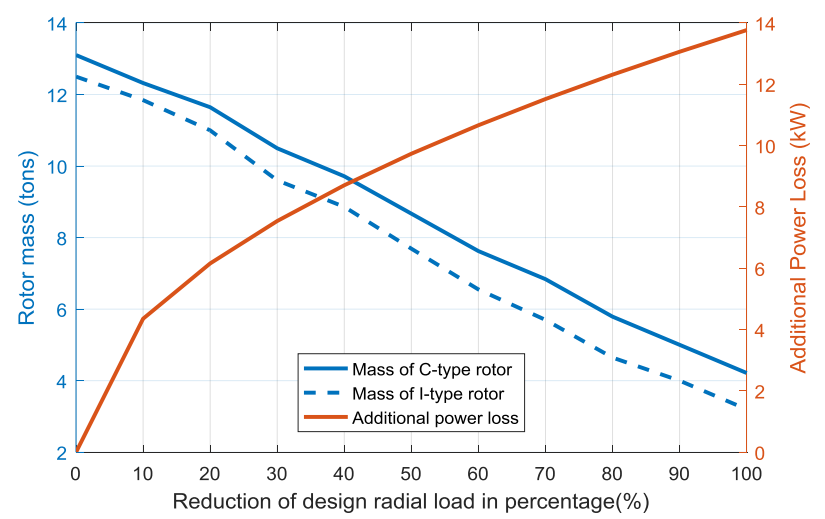

Figure 10: Mass of rotor and corresponding power loss against percentage reduction of design radial loads for $\mathrm{C}$-Structure rotor.

With an idea of the designed structural load and allowable deflection of structure, one can estimate the parameter $t_{\mathrm{w}}$ and $t_{\mathrm{d}}$ for the given configuration of rotor, which enables to estimate the mass of rotor using equation (10). This could be calculated either by using analytical solid mechanics relations or by using finite element software. In this case, this has been achieved by performing static finite element analysis of the structures in Autodesk Inventor platform. The rotor structures were constrained at the shaft and the net stress at outward direction was applied over the rotor cylindrical wall. The two parameters were systematically varied until the minimum thickness that does not violate the maximum allowable deflection of the rotor (in this case $0.7 \mathrm{~mm}$ ) is found. The process is repeated for both rotor structures and the two bearing configurations. To estimate the structural mass 
reduction by magnetic bearing the net stress on the cylindrical wall was reduced by certain fraction and the redefined structural parameters were achieved.

For a structure of a given material and mechanical property, deformation in it is a function of design load. In figure 10, the mass of rotor (both C-structure and I-structure) is shown on left $y$-axis and the power required to achieve is shown on right $y$-axis plotted against percentage reduction of radial loads. With the use of rolling element bearing the mass of $\mathrm{C}$ structured rotor was found to be 13 tons. This corresponds to zero additional power loss. At every reduction of the design load, the mass of rotor was found to be decreasing getting 4.5 tons at $100 \%$ reduction. The corresponding power required by magnetic bearing on the other hand was increased on the reduction of design loads.

One can see both bearing configurations and how the magnetic bearing contributes in reduction on designed electromagnetic loads. However, this reduction in loads by magnetic bearing comes at the expense of addition power required to produce such counteracting forces. For instance, it can be observed that in order to achieve 1.2 ton of mass saving, $10 \%$ of the design load has to be reduced which would cost around $4 \mathrm{~kW}$ of extra power in magnetic bearing. Thus, there shall be a trade-off between additional counteracting force by magnetic bearing and willingness to loss extra power.

\section{Conclusion}

The extra power required to operate magnetic bearing is higher than the frictional losses in rolling element bearing. The deviation of rotor from its axis of rotation is permanently present id the generator has rolling element bearings. While, as the forces are controlled locally at various sections with magnetic bearings, the rotor can always be brought back to its axis of rotation and the imbalance forces are minimised. The mass of rotor with the magnetic bearing tends to be less than that with rolling element bearing. The Magnetic bearing provides possibility to reduce some design loads on the structure. However this would come at the expense of additional power losses. Although evaluation based only on the ground of energy consideration and structural mass might seem insufficient, it does provide an indication of potential use of hybrid bearing system which could extract the benefit of both world. It is also obvious that the above evaluations should address the cost and maintenance requirement.

\section{References}

[1] P. Ivan, M. Ariola, and C. Giorgio, "The European offshore wind industry - key trends and statistics 2015," no. February, pp. 3-4, 2016.

[2] J. Broehl, R. R. Labastida, and B. Hamilton, A BTM NAVIGANT WIND REPORT Executive Summary: World Wind Energy Market Update 2015 International Wind Energy Development : 2015 - 2019. 2015.

[3] G. B. Failures, Durham E-Theses the Root Causes of Generator Bearing Failures. 2013.
[4] S. Caraher, "Bearing Options, including Design and Testing , for Direct Drive Linear Generators in Wave Energy Converters," Wear, 2011.

[5] G. Shrestha, Structural flexibility of large direct drive generators for wind turbines. 2013.

[6] G. Shrestha, D. J. Bang, H. Polinder, and J. A. Ferreira, "Structural flexibility: a solution for weight reduction of large direct-drive wind-turbine generators," IEEE Trans. Energy Convers. IF - 2.489, vol. 25, no. 3, pp. 732-740, 2010.

[7] K. Hart, A. McDonald, and H. Polinder, "Improved Cost of Energy Comparison of Permanent Magnet Generators for Large Offshore Wind Turbines," Ewea 2014, pp. 141-144, 2014.

[8] G. Bywaters, "Northern Power Systems WindPACT Drive Train Alternative Design Study Report," no. October 2004, pp. 1-404, 2004.

[9] SKF Group, Large Bearings- Bearings for Heavy Engineering Applications. VLT PRESS AB.

[10] A. McDonald, "Structural analysis of low speed, high torque electrical generatos for direct-drive renewable energy converters," 2008. 